\title{
Optimization of Main Parts of a Heavy Duty CNC MaChine CEnTRE USING A TOPOLOGiCAL OPTIMIZATION
}

\author{
Frantisek Sedlacek, Vaclava Lasova, Petr Bernardin, Petr Janda \& Marcel Svagr
}
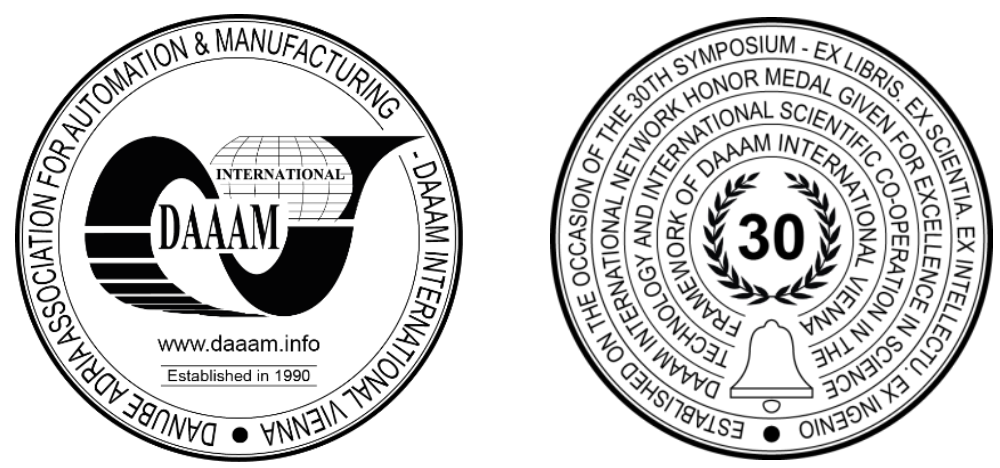

This Publication has to be referred as: Sedlacek, F[rantisek]; Lasova, V[aclava]; Bernardin, P[etr]; Janda, P[etr] \& Svagr, M[arcel] (2019). Optimization of Main Parts of Heavy Duty CNC Machine Centre Using Topological Optimization, Proceedings of the 30th DAAAM International Symposium, pp.0525-0532, B. Katalinic (Ed.), Published by DAAAM International, ISBN 978-3-902734-22-8, ISSN 1726-9679, Vienna, Austria

DOI: $10.2507 / 30$ th.daaam.proceedings.071

\begin{abstract}
The paper deals with optimizing of the headstock of the lathe part of the heavy duty CNC machining centre for 70 ton workpieces using topology optimization. The aim was to find a solution that minimizes compliance and reduces weight of the housing of headstock by $5 \%$. Topology optimization was done in the pre-processor Siemens Simcenter using the NX Nastran solver, which is based on the finite element method. The final structure of topology optimization was used as the concept for the basic layout of the main supporting ribs of the housing of the headstock. The obtained final design provides a high increase of the stiffness of the heavy machining centre in main directions.
\end{abstract}

Keywords: Machine centre; topology optimization; FEM; SIMP method.

\section{Introduction}

Determination of properties of the design (structure) is only one of the many steps in the product development. Main goal of engineers is finding a design that meets requirements for the stress, stiffness, reliability, weight etc. of the final product. A commonly used design process is very time consuming and often lead to ineffective design. For these reasons, the many types of the optimization techniques were created.

The goal of the optimization problem is often a maximization or minimization of the objective function, for example minimizing the weight or maximizing stiffness of the product [1], [2]. In order to find the optimal solution, the 'core' of the solution depending on a specific set of design variables must be expressed by a numerical value.

Mathematically the general optimization problem is mostly formulated as a minimization of the objective function (which can be easily transformed to the maximization by the minimizing the negative function) subject to constraints, it can be expressed as [3]: 
find $\mathbf{X}=\left\{\begin{array}{c}\boldsymbol{x}_{\mathbf{1}} \\ \boldsymbol{x}_{2} \\ \vdots \\ \boldsymbol{x}_{\boldsymbol{n}}\end{array}\right\}$ whitch minimizes $f(\mathbf{X})$

subject to constraints $\begin{cases}g_{i}(\mathbf{X}) \leq 0, & i=1,2, \ldots, m \\ h_{j}(\mathbf{X})=0, & j=1,2, \ldots, n\end{cases}$

where $\mathbf{X}$ is an $n$-dimensional vector called the design variables, $f(\mathbf{X})$ is termed the objective function and $g_{j}(\mathbf{X})$ and $h_{j}(\mathbf{X})$ are known as inequality and equality constraints, respectively they define the constraints of the design (design constraints). Structural optimization is one type from these optimizations. The goals of this type of the optimization is the find the best distribution of the material according to some given demands of structure (space). When objective function of the structural optimization is very often minimizing of the weight, displacement or the compliance (inverse function of the stiffness = strain energy). Exist many types of the structural optimizations, such as; geometry (size), topology, shape, topography and composite optimization.

Size optimization is one of the simplest types of the structural optimization. The main shape of the structure is known and into design variables of the solution belong physical properties of FEM meshes (or elements) [4].

Shape optimization is very similar to the size optimization: the main shape of the structure is know too but into design variables belongs geometrical parameters of the individual features of the model (holes, blends, etc.) [5].

Topography optimization is a special type of shape optimization, which allows change the shape of the 2D (shell) structures by inserting stamped ribs for better mechanical performance [6].

Composite optimization is special type of the optimization of the layup of the composite structures, which allows find the best thickness and direction of the main angles of the fibres of the individual plies of the laminate for required performance of the structure.

Topology optimization is a mathematical approach that optimizes material layout within a given design space, for a given set of loads and boundary condition in order to output the best structure performance and material distribution [7].

\subsection{Topology optimization}

Two main types of the approaches of the topology optimization exist: discrete and continuum. Discrete topology optimization solves the problem of determining the selection of a discrete set of elements that should be present in the structure (eg. trusses in beam structure). The best known methods of this approach are Evolutionary Structural Optimization (ESO) [8], Additive Evolutionary Structural Optimization (AESO) [9] and Bidirectional Evolutionary Structural Optimization (BESO) [10].

Topology continuum (also called Element-based) analyses the distribution of material in the design space. The result is a geometric arrangement that is defined by a shape consisting of void and material regions. The most commonly used methods are Solid Isotropic Microstructures with Penalization (SIMP) [11], [12], Rational Approximation of Material Properties (RAMP) [13], Optimal Microstructure with Penalization (OMP) [14], Non-Optimal Microstructures (NOM) and Dual Discrete Programming (DDP) [15].

In this case was used continuum approach with method SIMP. SIMP is the most commonly used, studied, well-defined and implemented in commercial software type of the topology optimization method. SIMP is a soft-kill type of the optimization, when the design volume is divided into a mesh of the $n$ elements ("solid isotropic solid microstructures"), each element has a pseudo-density $\rho_{e}$ (when $\rho_{e}=1$ we consider an element to be filled and an element with $\rho_{e}=0$ is consider to be a void element). The density function is written as

$$
\mathrm{E}=\rho^{p} \mathrm{E}^{0}, \quad \rho \in\left[\rho_{\text {min }}, 1\right], \quad p>1,
$$

where $p$ is the penalizing parameter that penalizes the elements of the design domain with intermediate densities to approach 0 or 1 and $\rho_{\min }$ is the value limit of the minimal density to avoid singularities. The optimization problem formulated in a nested formulation in equation (1.1) is then for SIMP written as

$$
\begin{aligned}
& \min _{x} f(\rho), \\
& \text { subject to } \quad\left\{\begin{array}{l}
0 \leq \rho \leq 1, \\
\text { State function constrain, } \\
\text { Manufacturing constraints. }
\end{array}\right.
\end{aligned}
$$

Minimalizing of the compliance $(\mathrm{C})$ or the volume $(\mathrm{V})$ are the most frequently used types of the objective function. Minimizing compliance refers to minimizing the energy absorbed by the structure when a load is applied, which is equivalent to maximizing the stiffness of a structure. This type of the objective function is in industrial application most used. 


\section{Current solution}

Headstock of the lathe part of the heavy duty CNC machining centre for 70 ton workpieces is shown further (fig. 1). Current housing of the headstock is cast from the cast iron GG-30 (DIN 1691). The mechanical parameters of the material are given in the

table 1. The basic shape of the headstock casting has continuous transverse ribs and one central longitudinal rib. Transverse ribs allow a simple installation of motors and gear set and the central longitudinal rib provides rigidity in the axial direction (workpiece prestressing, etc.). The present solution has axial stiffness $1098.5 \mathrm{kN} / \mathrm{mm}$, transverse stiffness $612.7 \mathrm{kN} / \mathrm{mm}$ and vertical stiffness $2110.4 \mathrm{kN} / \mathrm{mm}$ (according to numerical simulation) and the weight of the central housing is $8240 \mathrm{~kg}$.

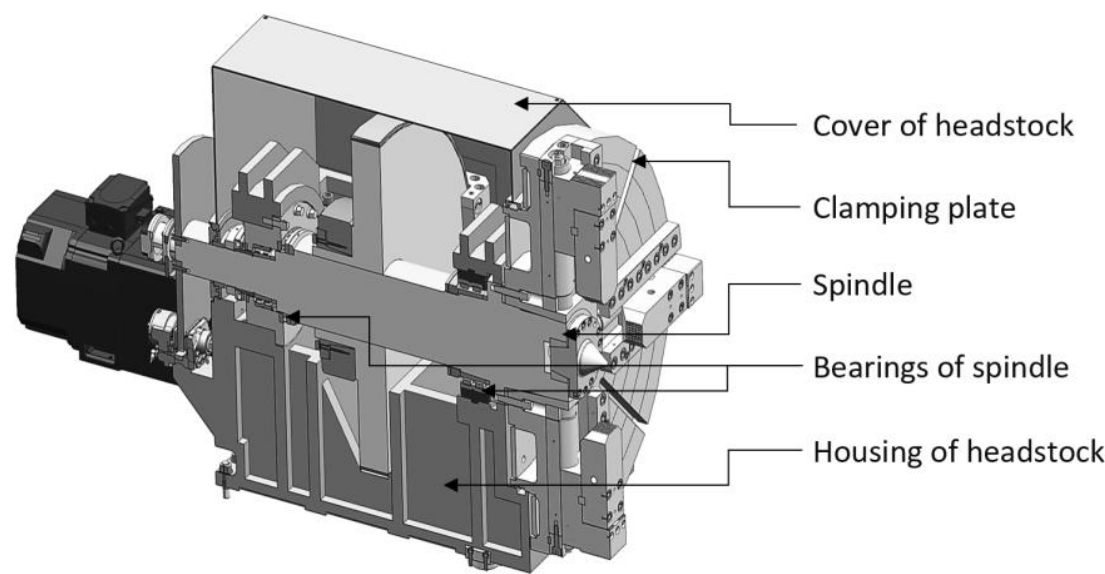

Fig. 1. Current solution (simplified model) of lathe part of the heavy duty CNC machining centre.

\begin{tabular}{lll}
\hline $\boldsymbol{\rho}\left[\mathrm{kg} / \mathrm{m}^{3}\right]$ & 7250 & Density \\
\hline$E[\mathrm{GPa}]$ & 126 & Elastic modulus \\
\hline$v[-]$ & 0.26 & Poisson's ratio \\
\hline$H B[-]$ & 285 & Hardness (Brinell) \\
\hline$R_{m}[\mathrm{MPa}]$ & 310 & Tensile strength \\
\hline$R_{m c}[\mathrm{MPa}]$ & 960 & Compression strength \\
\hline
\end{tabular}

Table 1. Mechanical properties of cast iron GG-30

\section{Structural optimization}

In first step, the design volume (where the resulting material flows can be located) for topology optimization was done. This volume was created with respect to the related components, their assembly and fastening of the headstock housing to the base part see fig. 2. The design volume is shown as grey and the volumes that have been subtracted are shown in colour (green - spindle area with bearing housing; yellow - drive housing including gearbox and red - central gear and mounting area).
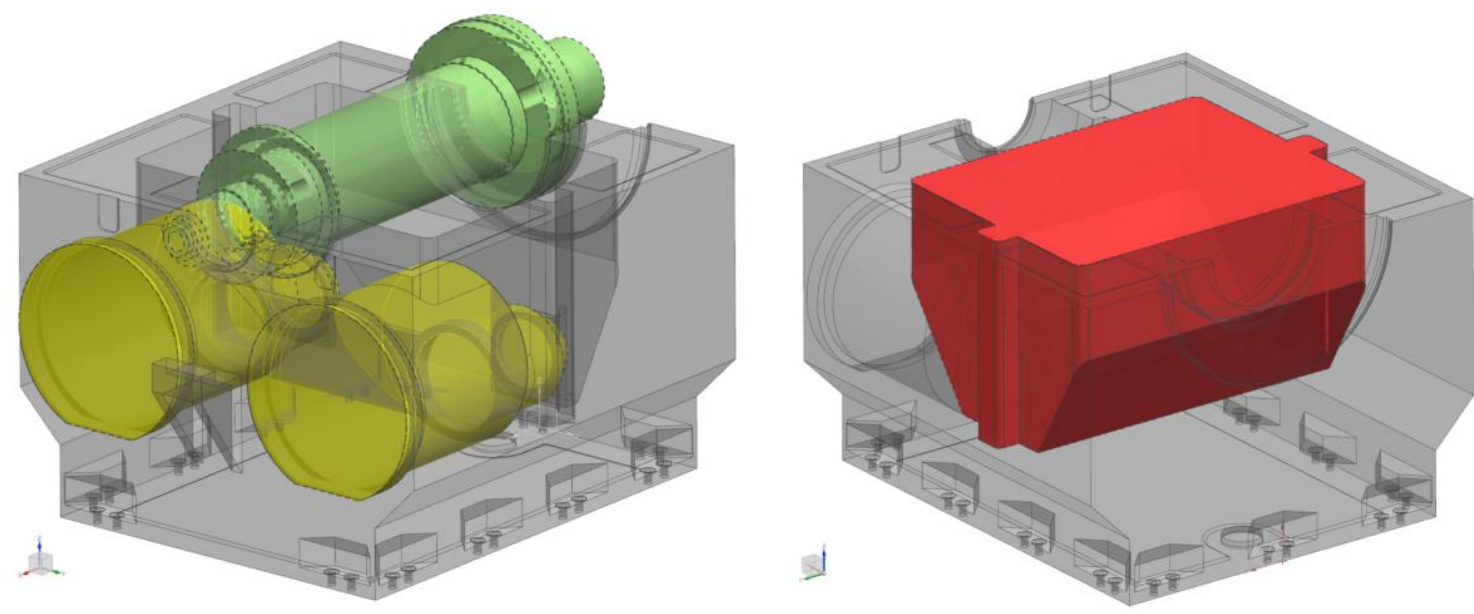

Fig. 2. Design volume for topology optimization (grey) and subtracted volumes (green - spindle area with bearing housing; yellow - drive housing including gearbox and red - central gear and mounting area). 
Topology optimization was done in the Siemens NX Simcenter software with the solver NX Nastran 2019.1 - SOL200 Topology optimization. The finite element model was created from 3D hybrid mesh (combination of the second order tetrahedral and hegagonal elements) see fig. 3. This type of mesh with uniform element size ensures a smoother material flow generation and second-order elements provide reduction of the checkerboard effect that may occur with densitybased methods of the topology optimization. The spindle and the housing were simplified, and conventional FE meshes were applied (from elements of the second order type CHEXA (20) or TETRA (10)). The bearings were simplified using 1D RBE2 meshes in combination with 1D CBUSH meshes to consider their adequate stiffness in main directions.

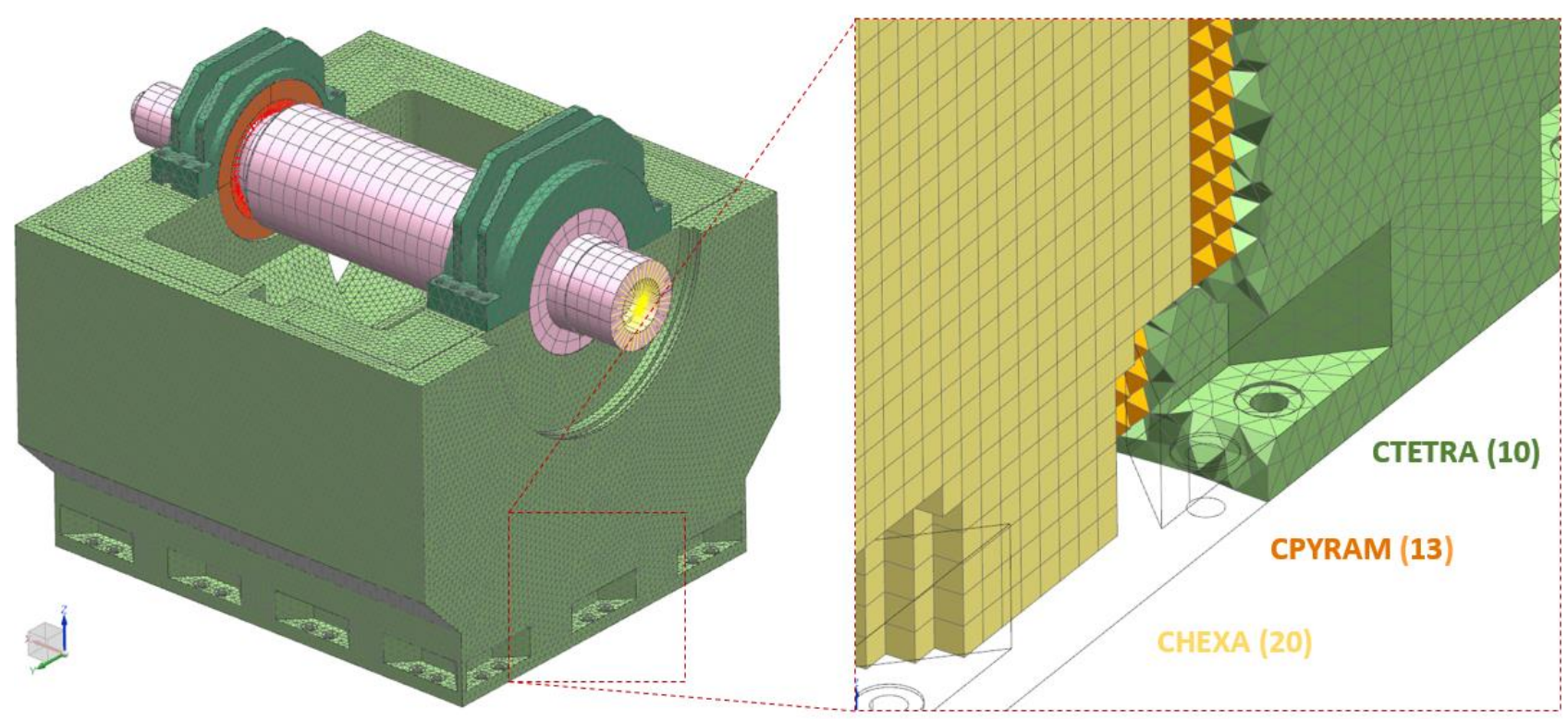

Fig. 3. FE mesh for topology optimization with detail of 3D hybrid mesh (core - hexagonal elements CHEXA(20) type; transition - pyramid elements CPYRAM(13) type and wrap - tetrahedral elements CTETRA(10) type).

The SIMP method with penalty $p=3$ was chosen for solution of the topology optimization. Minimization of compliance (equivalent to maximize the stiffness of the structure) was set as an objective function in combination with the design constraints for maximum weight of the design area $m_{\max }=7828 \mathrm{~kg}$ (compared to the current solution, the weight was reduced by $5 \%$ ). The modified volume of the headstock housing was chosen as the design area and the frozen area condition was applied to the surfaces intended to hold the headstock housing and related components (such as motors with gearbox housings, spindle bearings, etc.). This condition ensures that the selected structure is retained (the value of the pseudo-density of the assigned elements is set to 1) see fig. 4. Three optimization constraints were defined: the symmetry of the resulting structure in plane X-Z, the minimum $t_{\min }=40 \mathrm{~mm}$ and maximum $t_{\max }=95 \mathrm{~mm}$ wall thickness of the optimized structure.

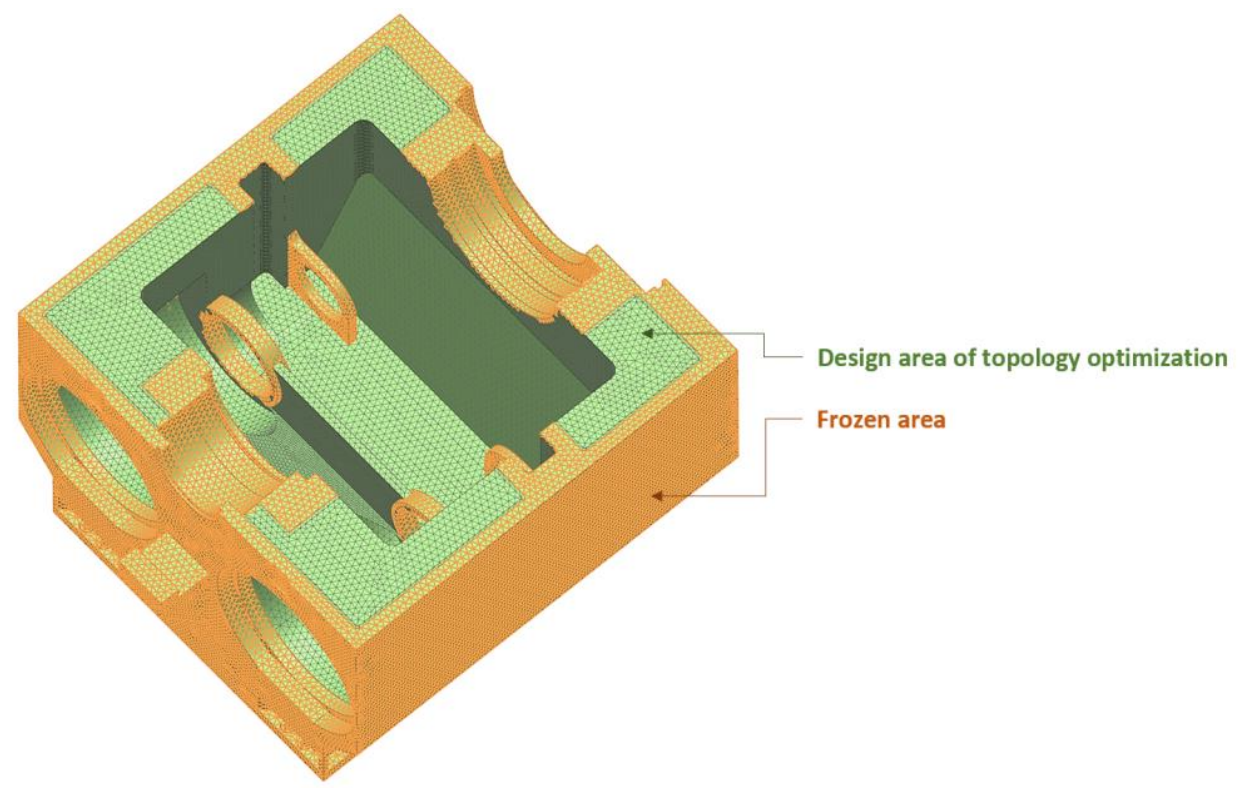

Fig. 4. Design area of the topology optimization with frozen areas. 
The best design cycle of the optimization was found after 248 cycles. The weight of the final structure $\left(m_{t o}=7509\right.$ $\mathrm{kg}$ ) and individual stiffnesses (axial stiffness $2009.6 \mathrm{kN} / \mathrm{mm}$, transverse stiffness $1062.8 \mathrm{kN} / \mathrm{mm}$ and vertical stiffness $3296.7 \mathrm{kN} / \mathrm{mm}$ ) were determined.

The final result (elements with psedo-density in range 0.65 - 1) was smoothed and exported to STL file. The smoothing process was done in two main steps: first smoothing process uses nodal values to determine which portion of each element to display; second level uses Laplace's method (by discrete approximation of Laplace's operator). The two-step smoothing process is given in Fig. 5.

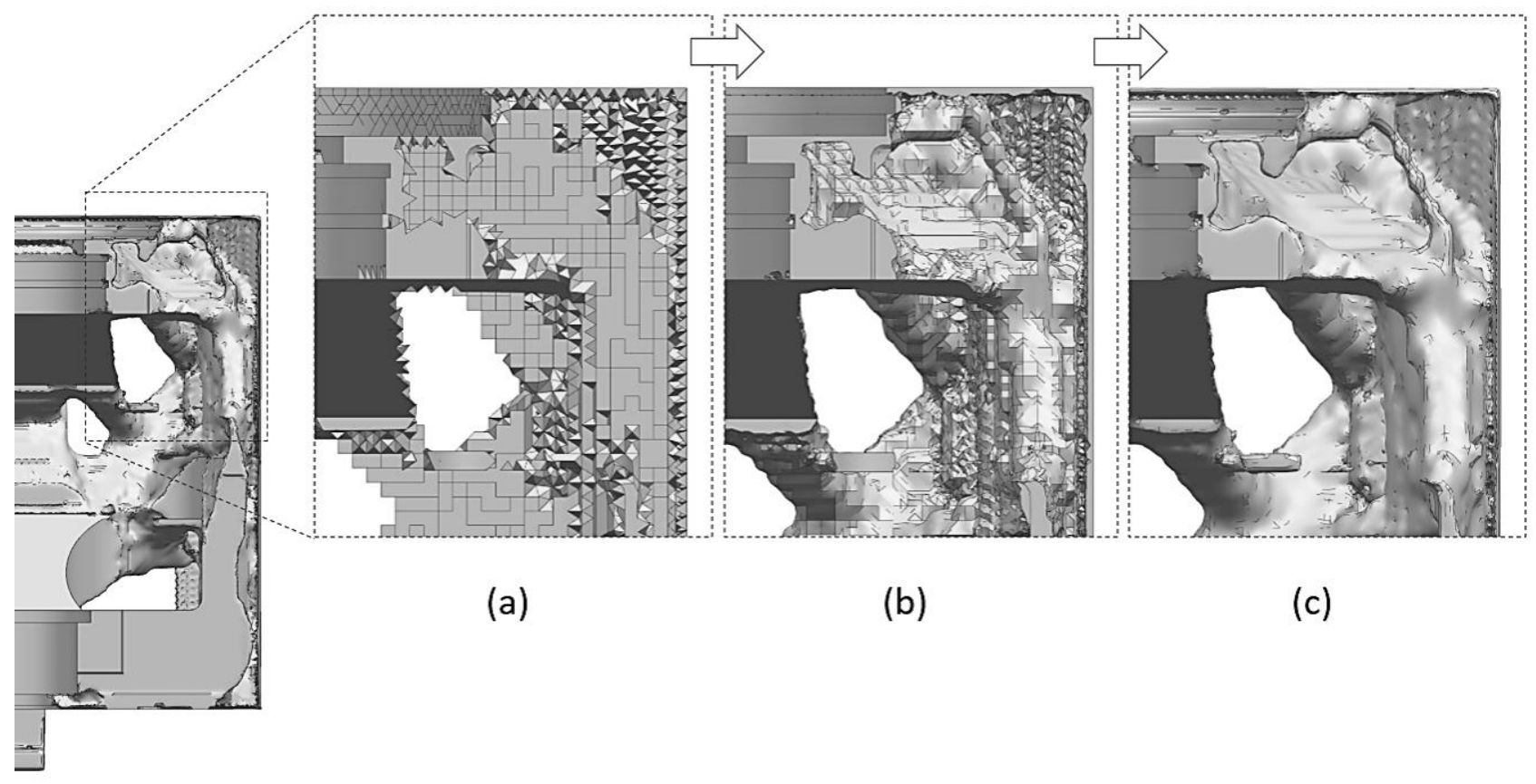

Fig. 5. Smoothing process of the final result (normalized material) of topology optimization: (a) detail without smoothing, (b) detail with nodal averages smoothing, (c) detail with nodal averages and Laplace method.

The final smoothed result of the topology optimization of the headstock housing is shown in fig. 6 . The basic shape of the result is characterized by the normalized material flow to the "V" in transverse vertical plane. Upper area of the housing was closed (especially in the rear area intended for mounting radial-axial spindle bearings). Furthermore, a central longitudinal rib was formed (transmit the axial load to the rear bearing, the radial load from the central pin of the headstock housing and a part of the vertical load from the weight of the workpiece).
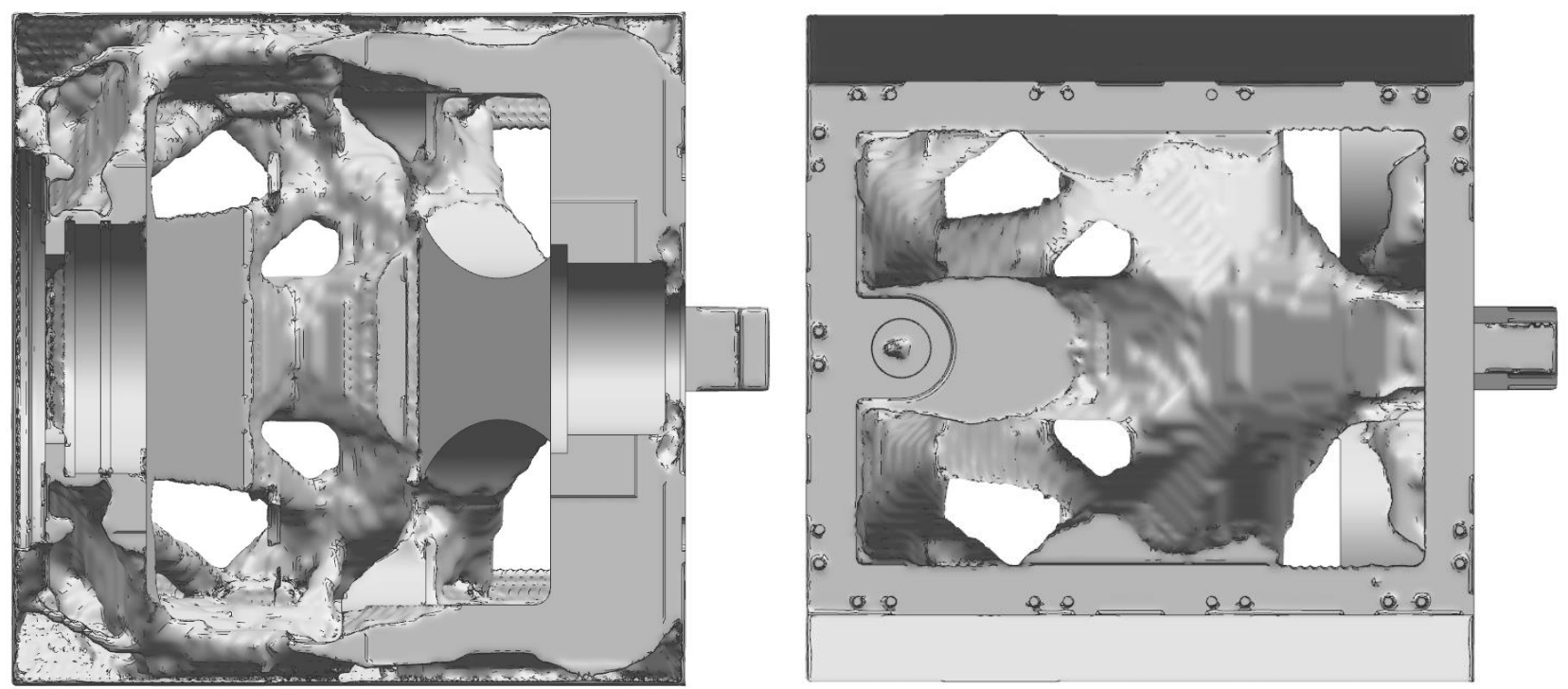

Fig. 6. Final smoothed result of topology optimization of headstock housing: top view (left), bottom view (right). 


\section{Verification of results of topology optimization}

The verification analysis was done because the results of the final stiffness of the topology optimization also contain elements that had a pseudo-density between $0-1$ and affect the overall stiffness of the structure. The normalized material (elements) with pseudo-density in range $0.65-1$ were exported into a separate solution and a homogeneous material was applied to all of them. The boundaries conditions were taken from topological optimization. The disadvantage of this procedure is that it is not possible to use the results (normalized material) with a smoothing function (fig. 7).

The change of the stiffness in main directions was found only about $1 \%$ in comparison with results from topology optimization (axial stiffness 1998,2 kN/mm, transverse stiffness 1058,1 kN/mm and vertical stiffness 3297,9 kN/mm).
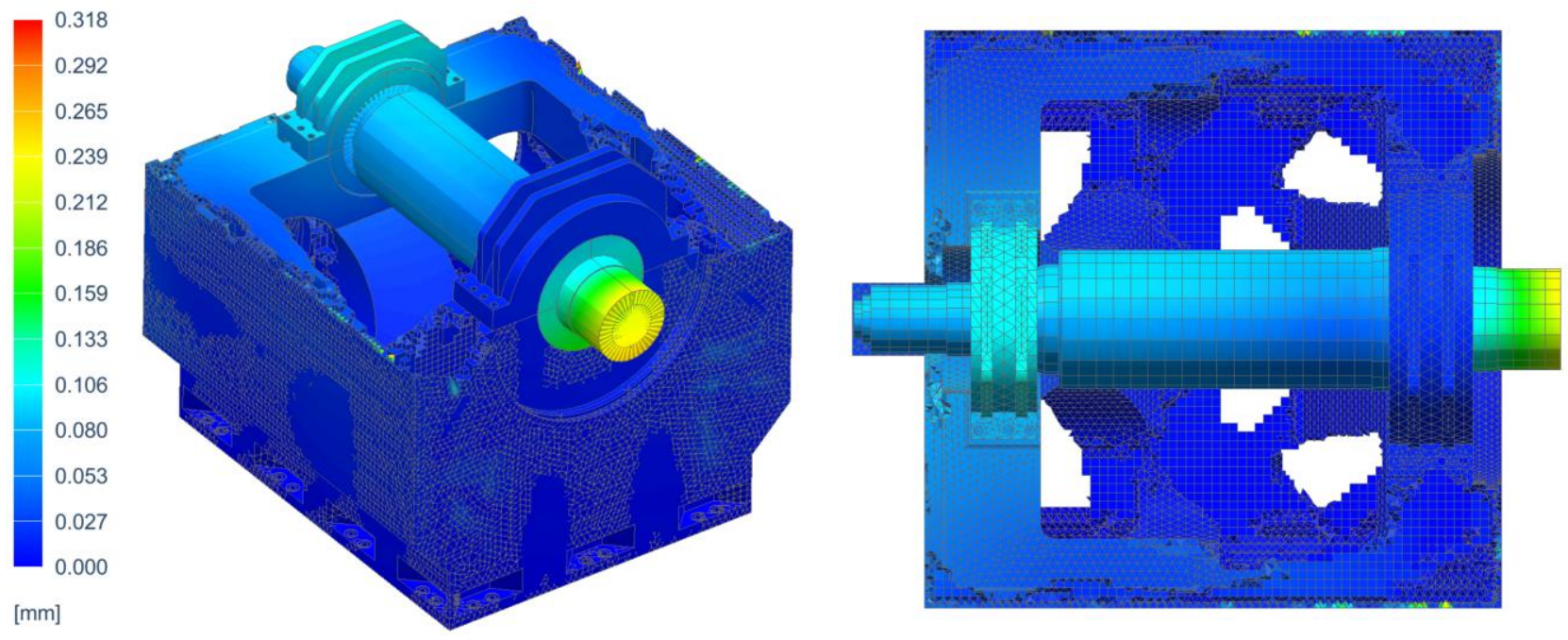

Fig. 7. CAD model of final design of housing of headstock.

\section{Final design of headstock}

The final shape of the housing of the headstock was created based on the results of the topology optimization. The individual material flows were simplified into basic ribs for ensure manufacturability. The final structure is especially characterized by two main inclined transverse ribs embedded to ' $\mathrm{V}$ ' and central longitudinal vertical rib. The final design of the headstock is shown in the fig. 8 .
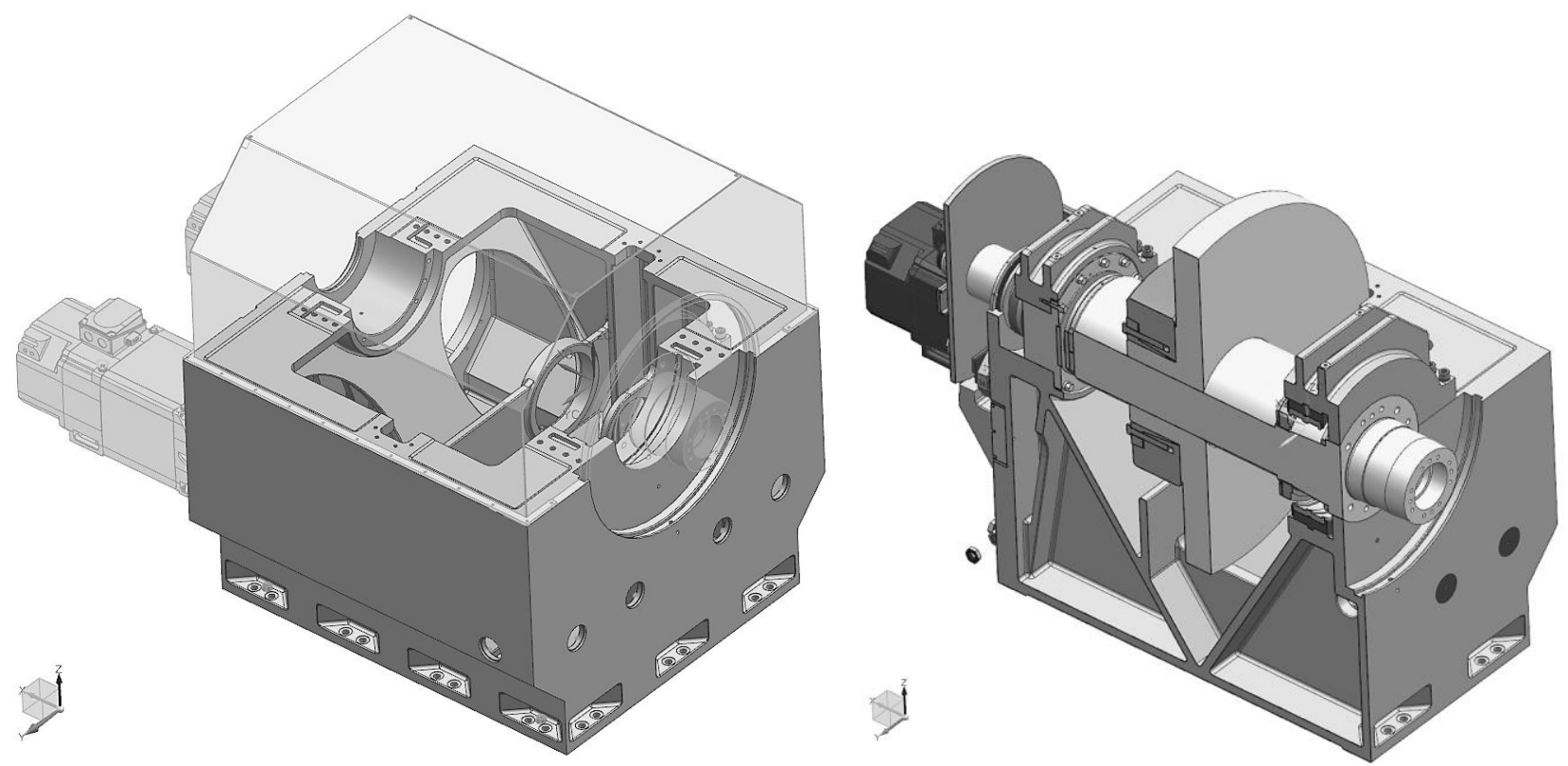

Fig. 8. CAD model of final design of housing of headstock. 


\subsection{Structural analysis of final design of headstock}

Structural analysis was done on the final design of the headstock for determination of the final stiffness and strength. The same type of the FEM meshes and boundary conditions as in topology optimization was used. The FEM model of the headstock and magnitude displacement are given in fig. 9.

From results of the displacements the axial stiffness $1441,2 \mathrm{kN} / \mathrm{mm}$, transverse stiffness $738,7 \mathrm{kN} / \mathrm{mm}$ and vertical stiffness $2508,4 \mathrm{kN} / \mathrm{mm}$ were determined and weight $7908 \mathrm{~kg}$.
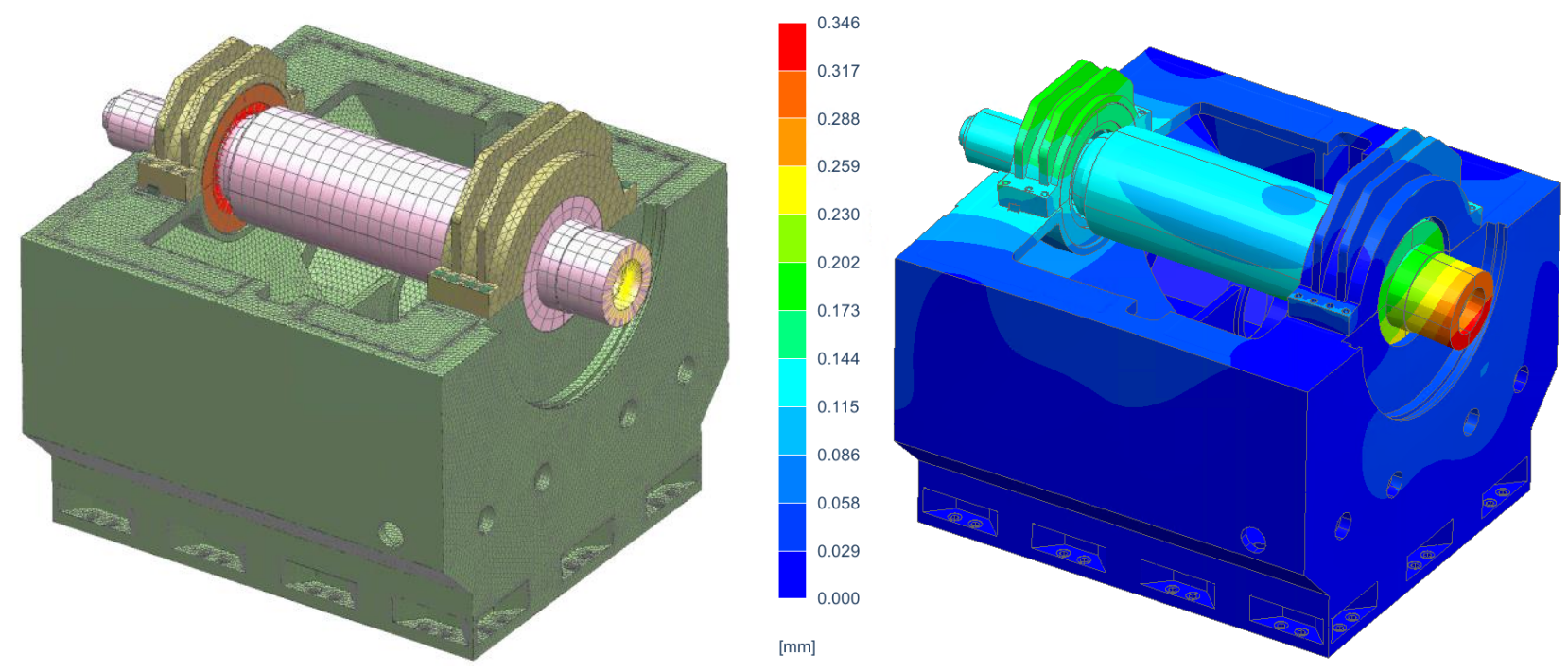

Fig. 9. FEM model of the final design of headstock (left), magnitude displacement [mm] (right).

\section{Comparison of results and discussion}

The comparison of the results of the current solution, final design, topology optimization and their verification are given in

table 2. It is possible see a significant decreasing in stiffness when results of the final design and topology optimization are compared. This is due to the adaptation of the 'bionic' material flows from results of the topology optimization into simple shapes that allow easy manufacture by casting. Using suitable wall thicknesses and the addition of holes for the fixing and removal of the mould cores also had a significant impact.

\begin{tabular}{lcccccc}
\hline & $\begin{array}{c}\text { Axial stiffness } \\
{[\mathrm{kN} / \mathrm{mm}]}\end{array}$ & $\begin{array}{c}\text { Dif. } \\
{[\%]}\end{array}$ & $\begin{array}{c}\text { Transverse stiffness } \\
{[\mathrm{kN} / \mathrm{mm}]}\end{array}$ & $\begin{array}{c}\text { Dif. } \\
{[\%]}\end{array}$ & $\begin{array}{c}\text { Vertical stiffness } \\
{[\mathrm{kN} / \mathrm{mm}]}\end{array}$ & $\begin{array}{c}\text { Dif. } \\
{[\%]}\end{array}$ \\
\hline Current solution & 1098,5 & 0 & 612,7 & 0 & 2110,4 & 0 \\
\hline Topology optimization & 2009,6 & +83 & 1062,8 & $+73,5$ & 3296,7 & +56 \\
\hline Verification of TO & 1998,2 & +82 & 1058,1 & $+72,7$ & 3297,9 & +56 \\
\hline Final design & 1441,2 & +32 & 738,7 & $+20,6$ & 2508,4 & +19 \\
\hline
\end{tabular}

Table 2. Comparison of individual solutions.

\section{Conclusion}

The aim of this paper was a structural optimization of the housing of the headstock of the lathe part of the heavy duty CNC machine centre. The topology optimization based on finite element method was used for finding of the optimal material distribution which ensures the minimization of compliance and reduces weight of the housing of headstock. The final design of the housing was created according basic character of results of the topology optimization (individual material flows were simplified into basic ribs for ensure manufacturability).

The found design indicate a significant increasing of the stiffness of the structure in main directions (up to $32 \%$ in axial direction, up to $21 \%$ in transverse direction and up to $19 \%$ in vertical direction) while the weight was reduced by $4 \%$. 


\section{Acknowledgments}

This article has been prepared under project FV10219 'Multifunctional machine for machining of large and complex shaped parts of rotary character, designed for power and renewables' under the auspices of the Ministry of Industry and Trade of the Czech Republic.

\section{References}

[1] K. Raz, M. Cechura, and Z. Chval, 2015. 'Upper crossbeam of free forging press optimization in order to improve mechanical properties and durability', Annals of DAAAM for, pp. 524-529.

[2] Z. Chval and M. Cechura, 2014. 'Optimization of power transmission on mechanical forging presses', Procedia Engineering, vol. 69, pp. 890-896.

[3] S. S. Rao, 2009. Engineering Optimization: Theory and Practice, 4 edition. Hoboken, N.J: Wiley.

[4] P. Christensen and A. Klarbring, 2009. An Introduction to Structural Optimization. Springer Netherlands.

[5] W. Nadir, I. Y. Kim, and O. de Weck, 'Structural Shape Optimization Considering Both Performance and Manufacturing Cost', in 10th AIAA/ISSMO Multidisciplinary Analysis and Optimization Conference, American Institute of Aeronautics and Astronautics.

[6] S. Kilian, U. Zander, and F. E. Talke, 2003. 'Suspension modeling and optimization using finite element analysis', Tribology International, vol. 36, no. 4, pp. 317-324.

[7] M. P. Bendsoe and O. Sigmund, 2004. Topology Optimization: Theory, Methods, and Applications, 2nd ed. Berlin Heidelberg: Springer-Verlag.

[8] Y. M. Xie and X. Huang, 2010. 'Recent developments in evolutionary structural optimization (ESO) for continuum structures', in IOP Conference Series: Materials Science and Engineering, vol. 10, p. 012196.

[9] O. M. Querin, G. P. Steven, and Y. M. Xie, 2000. 'Evolutionary structural optimisation using an additive algorithm', Finite elements in Analysis and Design, vol. 34, no. 3-4, pp. 291-308.

[10] O. M. Querin, V. Young, G. P. Steven, and Y. M. Xie, 2000. 'Computational efficiency and validation of bidirectional evolutionary structural optimisation', Computer methods in applied mechanics and engineering, vol. 189, no. 2, pp. 559-573.

[11] M. P. Bendsøe, 1989. 'Optimal shape design as a material distribution problem', Structural optimization, vol. 1, no. 4, pp. 193-202.

[12] M. Zhou and G. I. N. Rozvany, 1991. 'The COC algorithm, Part II: Topological, geometrical and generalized shape optimization', Computer Methods in Applied Mechanics and Engineering, vol. 89, no. 1-3, pp. 309-336.

[13] M. Stolpe and K. Svanberg, 2001. 'An alternative interpolation scheme for minimum compliance topology optimization', Structural and Multidisciplinary Optimization, vol. 22, no. 2, pp. 116-124.

[14] G. Allaire, 1997. 'The homogenization method for topology and shape optimization', in Topology optimization in structural mechanics, Springer, pp. 101-133.

[15] M. Beckers and C. Fleury, 1997. 'Topology optimization involving discrete variables', in Proceedings of the second world congress of Structural and multidisciplinary optimization: May 26-30 1997, Zakopane, Poland, pp. $533-538$. 